\title{
Perceptions and Receipt of Cancer Screening among African Americans: A Community Networks Program Project
}

\author{
Sylvie A. Akohoue1, Donna Kenerson'2 , Zudi-Mwak Takizala1, Katina Beard ${ }^{3}$, Marilyn Burress', \\ Helen Pinkerton', Jianguo Liu1, Kushal Patel' ${ }^{2}$, Margaret Hargreaves ${ }^{1}$
}

${ }^{1}$ School of Medicine, Meharry Medical College, Nashville, TN, USA

${ }^{2}$ Tennessee State University, Nashville, TN, USA

${ }^{3}$ Matthew Walker Comprehensive Health Center, Nashville, TN, USA

${ }^{4}$ Memphis Health Center, Memphis, TN, USA

${ }^{5}$ Southside/Dotson Community Health Center, Chattanooga, TN, USA

Email: saakohoue@mmc.edu

How to cite this paper: Akohoue, S.A., Kenerson, D., Takizala, Z.-M., Beard, K., Burress, M., Pinkerton, H., Liu, J.G., Patel, K. and Hargreaves, M. (2016) Perceptions and Receipt of Cancer Screening among African Americans: A Community Networks Program Project. Open Journal of Epidemiology, 6, 256-270.

http://dx.doi.org/10.4236/ojepi.2016.64025

Received: September 11, 2016

Accepted: November 20, 2016

Published: November 24, 2016

Copyright (c) 2016 by authors and Scientific Research Publishing Inc. This work is licensed under the Creative Commons Attribution International License (CC BY 4.0).

http://creativecommons.org/licenses/by/4.0/

\begin{abstract}
Objective: Minority groups constitute one of the nation's highest cancer risk groups. Historically, these groups have not been adequately informed about cancer, its prevention and/or treatment. The purpose of this study was to examine participants' receipt of cancer screening and to explore perceptions of barriers to and facilitators of cancer screening. Methods: A two-part study design consisting of a survey and focus group was conducted among African Americans residents of neighborhoods geographically defined as low-income areas of Chattanooga, Memphis, and Nashville in the state of Tennessee. The survey was administered to 1071 participants, and 12 focus groups were conducted with a total of 112 participants, with both sets of participants being residents of similarly defined underserved communities served by the community health centers. Results: Overall, $51 \%$ of surveyed respondents were females; the majority $(75 \%)$ had a yearly income of less than $\$ 25,000$; and $67 \%$ reported 12 years of education or less. Most surveyed respondents had a family history of cancer. More than $30 \%$ and $64 \%$ of male respondents over 50 years old did not receive prostate cancer and colorectal cancer screening, respectively; $58 \%$ of women 50 years and older were not screened for colorectal cancer; $28 \%$ of women over 40 years old did not receive breast cancer screening. Barriers to cancer screening included: lack of information about cancer screening and treatments, cost of cancer treatment and fear. The need for more information about cancer and cancer treatment, as well as the involvement of churches to increase cancer screening awareness was identified as facilitators. Conclusion: This study provides information into the structural and
\end{abstract}


psychological barriers in cancer screening. It describes the self-reported prevalence/frequency of screening among men and women in our target population, and the associated facilitators to screening.

\section{Keywords}

Cancer Screening, Barriers, Facilitators, African Americans

\section{Introduction}

Despite reports of recent declines in cancer deaths, racial and ethnic disparities in cancer incidence and mortality continue to exist for the most common types of cancer [1] [2] [3] [4]. Compared to non-Hispanic whites, African Americans men (275.5 vs. 214 per 100,000) and women (173 vs 151 per 100,000) have a higher death rate for cancer, with twice the death rates for both cervical and prostate cancers than non-Hispanic whites [5]. An unusual disparity is breast cancer, for which African Americans have lower incidence rates but higher death rates than non-Hispanic whites [5]. Among Hispanic women the incidence rates for cervical cancer are 15\% higher with 50\% less death rates than non-Hispanic whites [5].

In Tennessee, cancer remains the second leading cause of death, second only to heart disease [6]. Compared to other states, Tennessee has had the 5th highest cancer mortality rate for the overall population between 2002-2006 and 2006-2010 [7] [8]. Recent reports also indicate a disproportionately higher incidence of cancer (479.9 per 100,000) and mortality rate (198.2 per 100,000) among Tennessee residents [7]. In addition, Non-Hispanic Black Tennesseans were more likely to be diagnosed at late stages than Non-Hispanic whites, thus decreasing their odds of survival [8].

A major goal of both the American Cancer Society and the US Department of Health and Human Services has been to reduce and eliminate the disproportionate burden of cancer among racial and ethnic groups by using strategies such as expanding access to cancer screening and treatment, and developing patient Navigator Outreach and Chronic Disease Programs [9], which have been shown to improve compliance to screening [10] [11].

Despite the availability of screening methods for most common cancers, and the promotions of cancer screening tests through various health marketing campaigns, racial and ethnic minority groups are less likely to receive timely screening, which contributes to late stage of diagnosis and low survival rate among these groups [12] [13]. For example, studies showed that both uninsured, and underinsured African American women, who are predominantly poor, have relatively low cancer screening rates [13] [14] and are less likely to receive timely follow-up even after the initial screening [15]. Low utilization of cancer screening has also been reported among African American men from low socioeconomic backgrounds [16] [17].

Although there have been advances in understanding cancer cause and prevention, including new approaches to combating the disease, there is still a need for public edu- 
cation about cancer screening and treatments. Misconceptions about various cancers and their risks and barriers to screening must be investigated so that culturally appropriate programs can be developed to address them. The purpose of this study was to assess perceptions of cancer and cancer screening among low-income African Americans. Understanding individual feelings and thoughts associated with cancer screening could guide the development of new approaches that are specifically targeted at improving awareness and education efforts as well as developing new interventions directed to minority groups.

\section{Methods}

\subsection{Study Setting and Participants}

The Meharry Medical College-Community Networks Program (CNP) is one of the 23 Community Networks Program Centers (CNPCs) established by The NCI's Center to reduce cancer health disparities. The overarching goal of the CNP is to reduce and eliminate cancer health disparities through community-based research, education, and training so as to: 1) improve screening rates for cancer in African American communities; and 2) promote access to and use of cancer prevention strategies and treatments. To achieve this goal, the Meharry CNP has partnered with community health centers (CHCs) across the state of Tennessee, including the Southside/Dodson Community Health Center in Chattanooga, the Matthew Walker Comprehensive Health Center in Nashville, and the Memphis Community Health Center. These CHCs serve predominantly underserved populations in largely poor African American neighborhoods and were the centralized facilities for the catchment zip codes for this project.

We conducted a two-part study to assess participants' receipt of cancer screening and their perceived barriers to and facilitators of cancer screening. In both studies, participants ( $\geq 21$ years old) were low-income African Americans, English speaking, and residents of Chattanooga, Memphis, or Nashville, in Tennessee.

First (Part I), we surveyed approximately 1071 African Americans. Recruitment focused on areas that were based on the catchment zip codes for the three partnering community health centers: 37,203, 37,207, 37,208, 37,218 (Davidson County/Nashville, Matthews Walker Comprehensive Health Center); 37,403, 37,406, 37,408, 37,410, 37,411 (Southside \& Dodson Avenue Community Health Centers, Chattanooga, Hamilton County); and 38,105, 38,106, 38,108, 38,109, 38,114, 38,116, 38,118, 38,126, 38,127 (Memphis Health Center, Memphis, (Shelby County) [18] [19]. Flyers were posted at community health centers, grocery stores, barber and beauty shops, or any business or organization used regularly by the target population.

Survey items included: 1) demographic characteristics: age, sex, race, household annual income, education level, employment status, marital status, health insurance coverage); 2) medical characteristics: smoking status, family history of cancer, and annual medical visit within the past 12 months; and 3) receipt of screening exam or test for most common cancers such as prostate, breast, cervical, and colorectal cancers and time since receipt of cancer screening (data not showed except for breast cancer 
screening). BMI $\left(\mathrm{kg} / \mathrm{m}^{2}\right)$ was calculated from a self-report on weight and height respectively.

In part II of the study, a qualitative methodology with focus group discussions was used to identify perceived barriers to and facilitators of cancer screening. Letters detailing the purpose and place of the study were mailed to interested participants in the zip codes identified above with a follow up telephone call confirming the date and time of the focus groups. A total of 112 participants from the three participating CHCs through flyers posted at the CHCs participated in the focus groups. Erlanger Health Systems Review Board approved the Chattanooga protocols for the studies. The protocols for Memphis and Nashville were approved by the Meharry Medical College Institutional Review Board.

\subsection{Focus Group Study Procedures}

Health educators from participating community health centers in Chattanooga, Memphis, and Nashville were trained to moderate each of the focus group sessions. Face-to-face training of moderators was conducted by members of the Meharry Medical College, Prevention Research Unit (PRU) research team using the standardized Training Protocol for Focus Groups tool (Meharry Medical College-Community Networks Program [CHC-CNP]). The training tool was developed by the Meharry PRU research staff and CHC-CNP team members, and concentrated on the use of protocols that included specific moderator techniques, as well as practice scripts. This tool was used in conjunction with mock focus group sessions. Once the training was completed, each participating site was provided with the focus group training manual as a guide for explaining the focus group design, recruitment, logistics (setting up the rooms) and moderating strategies. As part of the face-to-face training process, an assessment of proficiencies was done using the standardized Assessing a Moderator's Competencies checklist (Simply Better Continuous Improvement). This checklist was designed to ensure that each moderator possessed the requisite knowledge and skills needed for successfully conducting a series of focus groups. Essential competencies were in the areas of analytical thinking, preparation, and background knowledge, as well as group dynamics and interpersonal skills. Prospective moderators were also required to receive training and certification in the Protection of Human Research Subjects. Focus groups were held at each of the participating $\mathrm{CHCs}$, and were coordinated and conducted by the trained CNP/CHC Coordinators (H.P., K.B., M.B.) there.

A total of 12 focus group discussions were conducted: six at Matthew Walker Comprehensive Health Center (Nashville), four at Southside \& Dodson Avenue Community Health Center (Chattanooga), and two at Memphis Health Center). Each group included between 4 and 12 participants. The focus groups were conducted to augment survey data collected during the first part of the study. Focus groups were convened until there was no new information being collected. In addition, selection criteria used in the recruitment of focus group participants were identical to selection criteria used in part I, which included age, gender, race, and resident zip codes. The moderator's 
guide, developed by the Meharry PRU research staff and CHC/CNP team members was used for all focus group discussions. The guide comprised questions and probes centered on participants' perceptions of barriers to and facilitators of cancer screening. Examples of questions included 1) What are some of the reasons people do not get tested for cancer? 2) What is the best way to go about encouraging people to get tested for cancer? 3) If you could create an ideal situation where everyone gets tested for cancer, how would you do that?

Signed written consent forms were obtained from all participants on-site before the start of each focus group session. Each focus group lasted approximately 2 hours and was audio- and video-taped. Participants were compensated with a $\$ 25$ gift card for their participation.

\subsection{Data Analysis}

\subsubsection{Cancer Screening Survey (Part I)}

Demographic characteristics and participants' knowledge and perceptions of cancer screening were expressed as percentages. Body mass indexes (BMI, $\left.\mathrm{kg} / \mathrm{m}^{2}\right)$ were calculated and grouped into three categories: normal $\left(18.5 \mathrm{~kg} / \mathrm{m}^{2} \leq \mathrm{BMI} \leq 24.9 \mathrm{~kg} / \mathrm{m}^{2}\right)$, overweight $\left(25 \mathrm{~kg} / \mathrm{m}^{2} \leq \mathrm{BMI} \leq 29.9 \mathrm{~kg} / \mathrm{m}^{2}\right)$, and obese $\left(\mathrm{BMI} \geq 30 \mathrm{~kg} / \mathrm{m}^{2}\right)$. All data were analyzed using SAS (version 9.1).

\subsubsection{Focus Groups (Part II)}

All focus sessions were professionally transcribed verbatim. ATLAS.ti 5.2 (1999) was used to organize and manage the data for thematic analysis. Two team members, experienced in qualitative data analysis, independently read through and coded each of the transcripts in the style of a grounded theory method of analysis [20]. Together, both members reviewed the coded transcripts for consistency, and updated their findings when new codes emerged during the process. Coding was hierarchical, with variation in a given theme being coded under subheadings. Validity was enhanced by comparing the researchers' findings and through group discussion [21]. This approach allowed barriers to and facilitators of cancer screening to be further understood.

\section{Results}

\subsection{Survey}

Approximately half (51\%) of surveyed respondents were females, and the majority were low income with a high school education (67\% reported 12 years or less of a high school education). Most participants were 35 years and older, overweight and obese (74\%) and had a family history of cancer (57\%). Participants' characteristics are summarized in Table 1. Of those who completed the cancer screening survey (males, $\mathrm{n}=$ 468; females, $\mathrm{n}=495), 4 \%(\mathrm{n}=17)$ of the male respondents reported being diagnosed with prostate cancer, and 13\% $(\mathrm{n}=62)$ and $10 \%(\mathrm{n}=49)$ of the females reported breast and cervical cancer, respectively. Examination of receipt of cancer screening revealed that the majority of the male respondents who were 45 years and older were not 
Table 1. Background characteristics of participants who completed the survey.

\begin{tabular}{|c|c|}
\hline Characteristics & $\mathrm{N}^{\mathrm{a}}(\%)$ \\
\hline \multicolumn{2}{|l|}{ Age (years) } \\
\hline \multicolumn{2}{|l|}{ Female } \\
\hline$<35$ & $174(32)$ \\
\hline $35-<50$ & $170(31)$ \\
\hline$\geq 50$ & $202(37)$ \\
\hline \multicolumn{2}{|l|}{ Male } \\
\hline$<35$ & $136(26)$ \\
\hline $35-<50$ & $180(34)$ \\
\hline$\geq 50$ & $209(40)$ \\
\hline \multicolumn{2}{|l|}{ Household annual income } \\
\hline$<\$ 25,000$ & $752(75)$ \\
\hline$\geq \$ 25,000$ & $250(25)$ \\
\hline \multicolumn{2}{|l|}{ Education } \\
\hline$<$ High school & $253(24)$ \\
\hline High school & $443(43)$ \\
\hline$>$ High school & $338(33)$ \\
\hline \multicolumn{2}{|l|}{ Employment status } \\
\hline Employed & $522(52)$ \\
\hline Unemployed & $481(48)$ \\
\hline \multicolumn{2}{|l|}{ Insurance coverage } \\
\hline Private/Employer group plan & $262(42)$ \\
\hline TennCare $^{\mathrm{b}}$ & $230(37)$ \\
\hline Medicare & $90(14)$ \\
\hline \multicolumn{2}{|l|}{ Smoking status } \\
\hline Current smoker & $334(33)$ \\
\hline Past smoker & $89(9)$ \\
\hline \multicolumn{2}{|l|}{ Family history of cancer } \\
\hline Yes & $596(57)$ \\
\hline No & $458(43)$ \\
\hline \multicolumn{2}{|l|}{ Type of cancer your relatives had } \\
\hline Breast cancer & $254(29)$ \\
\hline Cervical cancer & $148(18)$ \\
\hline Colorectal cancer & $94(12)$ \\
\hline Lung cancer & $238(28)$ \\
\hline Prostate cancer & $209(25)$ \\
\hline Other cancers & $231(30)$ \\
\hline \multicolumn{2}{|c|}{ Receipt of annual medical visit within last 12 months } \\
\hline Yes & $809(78)$ \\
\hline No & $231(22)$ \\
\hline \multicolumn{2}{|l|}{ Body mass index (BMI, $\mathrm{kg} / \mathrm{m}^{2}$ ) } \\
\hline $18.5 \leq \mathrm{BMI}<25$ & $247(26)$ \\
\hline $25 \leq \mathrm{BMI}<30$ & $304(32)$ \\
\hline $\mathrm{BMI} \geq 30$ & $392(42)$ \\
\hline
\end{tabular}

${ }^{\mathrm{a}} \mathrm{N}=1071 ;{ }^{\mathrm{b}}$ Tennessee Medicaid Program. 
screened for prostate cancer either with the PSA test (Figure 1). Most respondents 50 years and older had not received colorectal cancer screening by either fecal occult blood test (FOBT) or Sigmoidoscopy/colonoscopy. Most women respondents over the age of 40 had received breast cancer screening within the past 2 years (Figure 2). Among women $(\mathrm{n}=478)$ who completed the cervical cancer screening survey, $80 \%(\mathrm{n}=69,30$ years or younger), $85 \%(n=293,30-65$ years old $)$, and $93 \%(n=43$, over 65 years old $)$
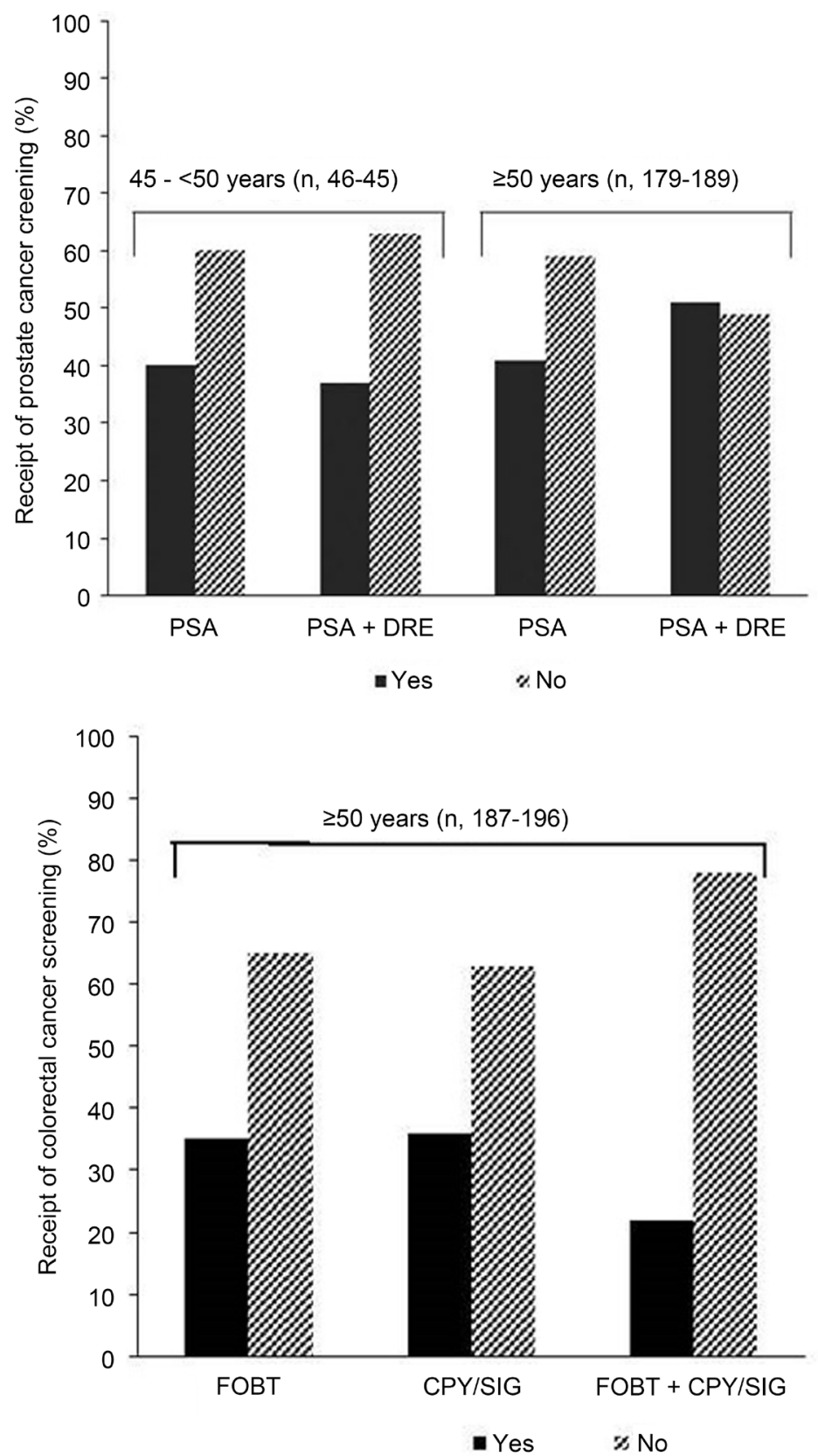

Figure 1. Distribution of receipt of prostate and colorectal cancer screening among men by age group. (Data are for men who completed the survey. Abbreviations: PSA, Prostate-specific antigen test; DRE, digital rectal exam; FOBT, stool test (fecal occult blood test); CPY/SIG, colonoscopy, sigmoidoscopy). 

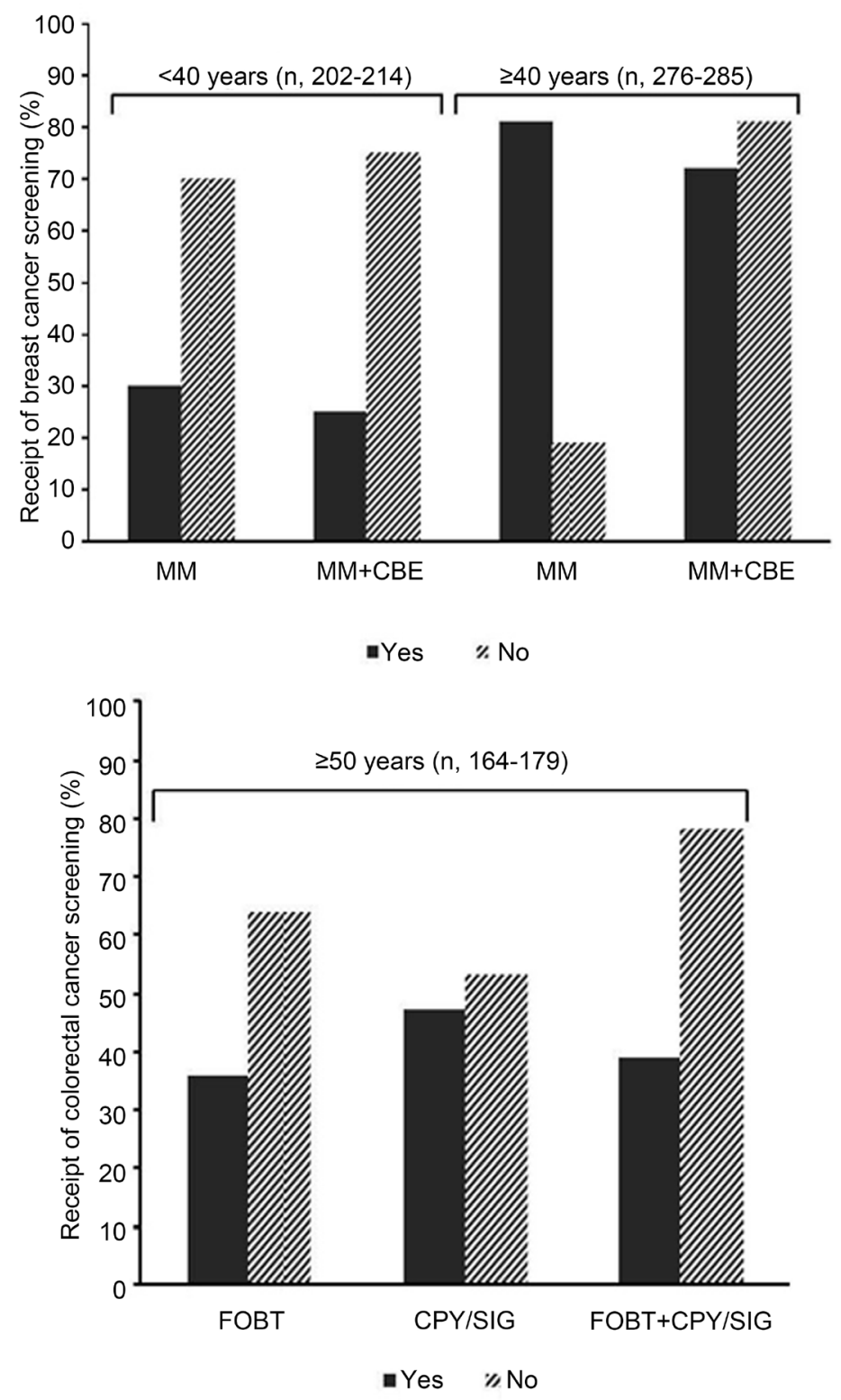

Figure 2. Distribution of receipt of breast and colorectal cancer screening among women by age group. (Data are for women who completed the survey. Abbreviations: MM, mammogram; CBE, clinical breast exam; FOBT, stool test (fecal occult blood test; CPY/SIG, colonoscopy, sigmoidoscopy)).

reported receiving cervical cancer screening. Distribution of participants' knowledge and perceptions of cancer screening are summarized in Table 2 and Table 3. Overall, more than two thirds of the respondents reported that smoking cigarettes or chewing tobacco, and having a relative who had cancer are more likely to cause cancer (Table 2). The majority of survey respondents also reported that eating high fiber foods, fruits and vegetables, and being active are less likely to cause cancer. About half of survey respondents reported no difference when asked whether or not being black or white causes cancer. More than half of the respondents perceived cancer treatments to be 
Table 2. Background characteristics of participants who completed the survey.

\begin{tabular}{cccc}
\hline Do you think ........ will cause cancer? & \multicolumn{3}{c}{ Respondents N (\%) } \\
\hline Having other family members who had cancer & $541(65)$ & $163(19)$ & $133(16)$ \\
Eating lots of fresh fruits and vegetables & $118(14)$ & $286(33)$ & $469(54)$ \\
Smoking cigarettes or chewing tobacco & $670(74)$ & $99(11)$ & $134(15)$ \\
Getting exercise & $99(12)$ & $311(37)$ & $432(51)$ \\
Having radiation treatments or X-rays & $271(36)$ & $261(35)$ & $214(29)$ \\
Having a lot of stress in your life & $363(45)$ & $281(35)$ & $159(20)$ \\
Eating foods high in fat & $417(51)$ & $267(33)$ & $136(17)$ \\
Being Black & $286(36)$ & $372(47)$ & $140(18)$ \\
Being White & $103(15)$ & $400(57)$ & $194(28)$ \\
Eating high fiber foods & $117(14)$ & $269(33)$ & $429(53)$ \\
\hline
\end{tabular}

Table 3. Distribution of participants' perceptions of cancer screening.

\begin{tabular}{|c|c|c|c|}
\hline \multirow{2}{*}{$\begin{array}{l}\text { Do you agree, have no opinion or disagree with the following } \\
\text { statements? }\end{array}$} & \multicolumn{3}{|c|}{ Respondents N (\%) } \\
\hline & Agree & $\begin{array}{l}\text { No } \\
\text { opinion }\end{array}$ & Disagree \\
\hline Getting cancer is a death sentence? & $296(36)$ & $508(62)$ & $20(2)$ \\
\hline If I had cancer, I would rather not know about it? & $256(30)$ & $566(67)$ & $20(2)$ \\
\hline $\begin{array}{c}\text { There are some things I can do to help me keep from getting } \\
\text { cancer? }\end{array}$ & $557(73)$ & $194(26)$ & $7(1)$ \\
\hline Getting tested for cancer is simple? & $447(68)$ & $206(31)$ & $4(1)$ \\
\hline It's too late for me to start worrying about cancer now? & $142(18)$ & $639(79)$ & $23(3)$ \\
\hline Cancer treatment would be more than I could afford? & $377(57)$ & $278(42)$ & $11(2)$ \\
\hline Getting treated for cancer is often worse than having it? & $320(53)$ & $277(46)$ & $11(2)$ \\
\hline $\begin{array}{l}\text { There are certain kinds of cancer that can be cured easier than } \\
\text { other kinds? }\end{array}$ & $518(76)$ & $158(23)$ & $4(1)$ \\
\hline $\begin{array}{l}\text { If you get treated for cancer early, you are more likely to be able } \\
\text { to return }\end{array}$ & $559(78)$ & $158(22)$ & $4(1)$ \\
\hline \multicolumn{4}{|l|}{ to your normal life? } \\
\hline Getting proper treatment for cancer is easy? & $337(57)$ & $249(42)$ & $8(1)$ \\
\hline
\end{tabular}

expensive and worse than getting the disease itself, and some (30\%) preferred not to know they had cancer (Table 3 ). Most respondents (80\%) perceived that with early treatment of cancer one is more likely to return to normal life.

\subsection{Focus Groups}

Twelve focus group discussions were conducted as noted earlier, and ranged between 4 and 12 participants per group. During the focus group discussions, participants were asked: What are some of the reasons people do not get tested for cancer? 
Participants' accounts indicated a number of existing interrelated factors that might contribute to the delay or cause individuals to forego cancer screening. Barriers to cancer screening that emerged from the analysis of the transcripts fell into two categories: structural barriers and psychosocial barriers.

\subsubsection{Structural Barriers}

Structural barriers were identified as factors that affect or hinder the ability of individuals to access cancer screening. In this study, they included health education and cost of care. Not knowing enough about cancer in general was expressed among focus group participants as key barriers to cancer screening: "Our biggest problem, we re not educated enough to know that there's several different kinds of cancer."

"I personally think it should be one-on-one cancer education" and "I did not know that... Some of the people that do get cervical cancer. A lot of women don't know that." Participants also identified that lack of information about existing cancer screening as a preventive tool is an important barrier to cancer screening: "If you are not really high risk or going for medical attention regularly... you don't even know that you need to be tested. So, there should be some type of red light to let you know that that's what you need to do."

The lack of health education was also expressed in the area of cancer treatments. Participants' lack of awareness about potential cancer treatments was another reason for not taking part in cancer screening as illustrated by the following statement " $A$ lot of people don't even know if chemotherapy works."

Cost of care was another structural barrier which hindered individuals' ability to participate in cancer screening. Participants were generally aware of free or low cost cancer screening services but their major concerns were about the costs associated with subsequent treatments in the event they were diagnosed with cancer: "It boils down to, even if you found out you had it (cancer) now you got to figure out how you're going to come up with the money, if there's a cure, to even pay for the medicine to cure it."

"I would not be able to take care of myself, and a lot of people who already struggle don't want to think about how they would pay or what they would do... I don't know if I would really want to deal with it."

Lack of health insurance was often expressed as a significant barrier to cancer screening: "I still bring up the issue of insurance... You have to have good health insurance and a lot of times it boils down to payment. That's the main thing." Participants also spoke about time commitment as a factor, typically referring to the time that will be needed to care for oneself: "I would not be able to take care of myself... I don't know if I would really want to deal with it."

\subsubsection{Psychosocial Barriers}

Psychosocial barriers were identified as factors related to internal beliefs and attitudes. Fear emerged as a major theme among psychosocial barriers. Participants' expression of fear had different meanings. Some fear cancer and often perceived it as an incurable, and debilitating disease with death as the outcome: “... So when you tell me cancer, I 
almost feel like that's automatically death right there. I don't want to deal with it, don't want to talk about it." Another category of fear expressed by participants was associated with their personal experiences with family members and friends who died from cancer. " $P m$ my father's only child and he died of cancer. $P$ ve always guessed it's in my genes. That word scares me. I fear it." "... just like I said, my mom, she passed from it. ... as soon as they operated she was gone. I fear it, just like that."

"It's (cancer) a slow, killing death. The last 10 years I have known seven people that got cancer, prostate, lung, and things like that. My uncle, my cousin, one of my best friends, his dad died from prostate cancer."

For others, the willingness to participate in cancer screening was diminished by the fear of knowing that they could have cancer: "I don't want to know I have cancer... You know the outcome is death."

Despite the existing fear, there was some acknowledgement by some focus group participants that having relatives who died from cancer motivated them to seek information: "I lost two sisters to breast cancer at the same time and it made me kind of get interested in going to the doctor... I'd rather know it and then I can get it treated before it gets into the later stages that can kill me. If you know about it early, you may get it right into remission."

\subsubsection{Facilitators}

In response to what would be the best way to facilitate and encourage cancer screening, provider-patient interaction was identified, particularly having some health education from providers and adequate time with providers during clinic visits: "They do teach but it depends on how sick you are. That's just my experience, depending on how sick you are, because if you are going in there for a regular check-up, no they are not teaching you, they' re moving you along."

"They come in and out so quick, they don't have time to even speak to you... A lot of them want to get you in and get you out, and they don't take the time to answer your questions. They act like you ask too many questions, they just don't give the time."

Community outreach involving churches and the medical community were expressed as facilitators of cancer screening. One participant noted: "If you look around in our community it's not just about cancer..., educate them (people) and tell them what's good for them. Take it to the churches because 90 percent of the people in our community go to some church" Another participant echoed the involvement of medical students: "Have medical students come into the program, go door-to-door."

Other facilitators, including the need for patients to be proactive and some suggestions of self-reliance were also mentioned during the focus group discussions: "Some people go (to the doctor) and never say a word... they never asked questions. You just have to stand up... I make my doctor talk to me. I ask questions."

There was also the suggestion that individuals should seek information themselves. One participant stated: “... Doctors are good, but do the footwork, do some research, check out yourself and quit relying on everybody else to do it."

When asked to describe an ideal situation where everyone gets tested for cancer, par- 
ticipants expressed the need for mandatory testing and community-based screening programs. Having mandatory testing was perceived as an effective strategy for ensuring that individuals are screened for cancer: "If you made it mandatory, then everybody would have to do it." Establishing community-based screening programs was viewed by participants as a way to address some barriers to cancer screening, such as transportation: "The people that work at the organizations coming out to the community, being hands-on with the community. I know, they need to come out in the neighborhoods, because if they don't come out we are not going to know (about health care programs), because we are not going to go to the doctor." Participants also saw this approach as an opportunity to increase awareness to cancer screening.

\section{Discussion}

Studies have shown that minority groups are among the nation's highest cancer risk groups [1] [2] [3] [4] [5]. These groups also have relatively low cancer screening rates [13] [14] and are less likely to receive timely follow-up even after the initial screening [15]. The current study explored barriers to and facilitators of cancer screening among African Americans residents of neighborhoods geographically defined as low-income areas in Chattanooga, Memphis, and Nashville, in the state of Tennessee.

Focus group participants identified several structural barriers, including lack of information about cancer and cancer screening, and the high cost associated with cancer treatments. Fear from the disease itself, fear of being diagnosed of having cancer, and fear related to impact of cancer on loved ones emerged as major psychological barriers to cancer screening. Results from our survey show that more than two thirds of male respondents over 45 years old had not received prostate cancer and colorectal cancer screening. Although the majority of female respondents reported receipt of cervical cancer screening, more than half of women respondents 50 years and older had not been screened for colorectal cancer, and the majority of those younger than 40 years had not received breast cancer screening. These discrepancies may be attributed to the psychological barrier expressed by focus group participants.

Although advances in understanding cancer research, especially in terms of personal behaviors and environmental factors, have set the stage for new approaches to combating the disease, having a better understanding of the factors that could facilitate the diffusion of health information to minority populations is critical in reducing existing cancer disparities. Similar to other reports [22] [23], data from this study also reveal that low awareness of cancer, its prevention and treatment exist among minority groups, suggesting the need to inform the socioeconomically disadvantaged population about cancer risks and risk reduction.

Reports have indicated that minority groups, particularly African Americans, appear to prefer being reached through personal contacts, in familiar surroundings, by persons who are known or familiar to them, such as close friends, family, or respected leaders [24] [25]. In this study, the role of providers was identified as a key facilitator to cancer screening. Providers' involvement in offering patients complete and clear information 
about cancer and the benefit of cancer screening could overcome the psychological barrier voiced by participants. During the focus group discussions, participants expressed the need for community churches to be involved in the dissemination of health information. Although such a community-based approach has promise it may require the recognition of the community as a unit of identity, and the need to build on strengths and resources within the community. It is also equally important to promote a co-learning and empowering process that attends to social inequalities, and to have a long-term commitment of all partners involved [26].

This study has a number of limitations. Although the focus group discussions were conducted at three sites, we were not able to compare how participants' perceptions differed between sites and by gender. Another limitation is that we intended to have 6 focus groups with 8 to 10 participants for each focus group discussion but attendance was lower, particularly at the Southside \& Dodson Avenue Community Health Center in Chattanooga, and the Memphis Health Center. This may limit the generalization of the study results. Despite these limitations, this study highlights perceptions, and beliefs that temper participants' interest in participating in cancer screening.

It is well established that cancer screening can lead to early detection, and when caught early most common cancers can be treated effectively, resulting in fewer cancer deaths [27] [28]. Through features of the multi-method approach, there was concordance between some variables associated with the survey and the focus groups, thus validating similar issues between the two target groups. The survey identified the scope of the problem, and the focus groups provided information about the depth of the problem.

\section{Conclusion}

Addressing the structural and psychological barriers to cancer screening is critical in improving cancer screening rates among minority groups. The associated facilitators to cancer screening reported in this study could guide the development of new and effective strategies. Such strategies will require programs and interventions tailored to target populations, particularly those from underserved communities.

\section{Acknowledgements}

This study was supported by the National Institute of Health and The National Cancer Institute (grant \# 5U01CA114641).

\section{References}

[1] American Cancer Society (2015).

http://www.cancer.org/research/cancerfactsstatistics/cancerfactsfigures2015/index

[2] DeSantis, C.E., Fedewa, S.A., Goding Sauer, A., Kramer, J.L., Smith, R.A. and Jemal, A. (2016) Breast Cancer Statistics, 2015: Convergence of Incidence Rates between Black and White Women. A Cancer Journal for Clinicians, 66, 31-42. http://dx.doi.org/10.3322/caac.21320

[3] McCarthy, A.M., Yang, J. and Armstrong, K. (2015) Increasing Disparities in Breast Cancer 
Mortality from 1979 to 2010 for US Black Women Aged 20 to 49 Years. American Journal of Public Health, S3, 446-448. http://dx.doi.org/10.2105/AJPH.2014.302297

[4] Antwi, S., Tucker, T.C., Coker, A.L. and Fleming, S.T. (2013) Racial Disparities in Survival after Diagnosis of Prostate Cancer in Kentucky, 2001-2010. American Journal of Men's Health, 7, 306-316. http://dx.doi.org/10.1177/1557988312473774

[5] Centers for Disease Control and Prevention (2015) Cancer Rates by Race/Ethnicity and Sex. http://www.cdc.gov/cancer/dcpc/data/race.htm

[6] Tennessee Department of Health (2014) Tennessee Deaths 2013. https://www.tn.gov/assets/entities/health/attachments/TnDeaths13.pdf

[7] Li, Q. and Whiteside, M.A. (2009) Cancer in Tennessee 2002-2006. https://www.tn.gov/assets/entities/health/attachments/Cancer_Tennessee_2006-2010.pdf

[8] Li, Y., Bauer, A.M. and Whiteside, M.A. (2013) Cancer in Tennessee, 2006-2010. https://www.tn.gov/assets/entities/health/attachments/Cancer_Tennessee_2006-2010.pdf

[9] American Cancer Society-American Cancer Society Cancer Action Network (2009) Cancer Disparities, a Chart Book. http://action.acscan.org/site/DocServer/cancer-disparities-chartbook.pdf

[10] Jandorf, L., Gutierrez, Y., Lopez, J., Christie, J. and Itzkowitz, S.H. (2005) Use of a Patient Navigator to Increase Colorectal Cancer Screening in an Urban Neighborhood Health Clinic. Journal of Urban Health, 82, 216-224. http://dx.doi.org/10.1093/jurban/jti046

[11] Battaglia, T.A., Roloff, K., Posner, M.A. and Freund, K.M. (2007) Improving Follow-Up to Abnormal Breast Cancer Screening in an Urban Population. A Patient Navigation Intervention. Cancer, 109, 359-367. http://dx.doi.org/10.1002/cncr.22354

[12] American Cancer Society (2013) Cancer Facts \& Figures for African Americans 2013-2014. http://www.cancer.org/research/cancerfactsfigures/cancerfactsfiguresforafricanamericans/c ancer-facts-figures-african-americans-2013-2014

[13] Leeks, K.D., Hall, I.J., Johnson-Turbes, C.A., Kamalu, N. and Zavahir, Y. (2012) Formative Development of a Culturally Appropriate Mammography Screening Campaign for LowIncome African American Women. Journal of Health Disparities Research and Practice, 5, $42-61$.

http://digitalscholarship.unlv.edu/cgi/viewcontent.cgi?article=1149\&context=jhdrp

[14] Coughlin, S.S., Uhler, R.J., Bobo, J.K. and Caplan, L. (2004) Breast Cancer Screening Practices among Women in the United States, 2000. Cancer Causes Control, 15, 159-170. http://dx.doi.org/10.1023/B:CACO.0000019496.30145.62

[15] Karcher, R., Fitzpatrick, D.C., Leonard, D.J. and Weber, S. (2014) A Community-Based Collaborative Approach to Improve Breast Cancer Screening in Underserved African American Women. Journal of Cancer Education, 29, 482-487. http://dx.doi.org/10.1007/s13187-014-0608-Z

[16] Fedewa, S. A., Etzioni, R., Flanders, W. D., Jemal, A. and Ward, E. M. (2010) Association of Insurance and Race/Ethnicity with Disease Severity among Men Diagnosed with Prostate Cancer, National Cancer Database 2004-2006. Cancer Epidemiology, Biomarkers and Prevention, 19, 2437-2444. http://dx.doi.org/10.1158/1055-9965.EPI-10-0299

[17] Miller, D.C., Litwin, M.S., Bergman, J., Stepanian, S., Connor, S.E. and Kwan, L. (2009) Prostate Cancer Severity among Low-Income, Uninsured Men. Journal of Urology, 181, 579-584. http://dx.doi.org/10.1016/j.juro.2008.10.010

[18] Patel, K., Kenerson, D., Wang, H., Brown, B., Pinkerton, H., Burress, M., Cooper, L., Canto, M., Ukoli, F. and Hargreaves, M. (2010) Factors Influencing Prostate Cancer Screening in Low-Income African Americans in Tennessee. Journal of Health Care for the Poor and 
Underserved, 21, 114-126. http://dx.doi.org/10.1353/hpu.0.0235

[19] Patel, K., Kanu, M., Liu, J., Bond, B., Brown, E., Williams, E., Theriot, R., Bailey, S., Sanderson, M. and Hargreaves, M. (2014) Factors Influencing Breast Cancer Screening in Low-Income African Americans in Tennessee. Journal of Community Health, 39, 943-950. http://dx.doi.org/10.1007/s10900-014-9834-x

[20] Glaser, B.G. and Strauss, A.L. (1967) The Discovery of Grounded Theory: Strategies for Qualitative Research. Aldine Pub. Co., Chicago.

[21] Barbour, R.S. (2001) Checklists for Improving Rigour in Qualitative Research: A Case of the Tail Wagging the Dog? British Medical Journal, 322, 1115-1117. http://dx.doi.org/10.1136/bmj.322.7294.1115

[22] Hawkins, N.A., Benard, V.B., Greek, A., Roland, K.B., Manninen, D. and Saraiya, M. (2013) Patient Knowledge and Beliefs as Barriers to Extending Cervical Cancer Screening Intervals in Federally Qualified Health Centers. Preventive Medicine, 57, 641-645. http://dx.doi.org/10.1016/j.ypmed.2013.08.021

[23] Hawkins, N.A., Cooper, C.P., Saraiya, M., Gelb, C.A. and Polonec, L. (2011) Why the Pap test? Awareness and Use of the Pap Test among Women in the United States. Journal of Women's Health, 20, 511-515. http://dx.doi.org/10.1089/jwh.2011.2730

[24] Oh, A., Shaikh, A., Waters, E., Atienza, A., Moser, R.P. and Perna, F. (2010) Health Disparities in Awareness of Physical Activity and Cancer Prevention: Findings from the National Cancer Institute's 2007 Health Information National Trends Survey (HINTS). Journal of Health Communication, 15, 60-77. http://dx.doi.org/10.1080/10810730.2010.522694

[25] Lynch, P.D. and Rorus, D.L. (1982) Cancer Information for Blacks: A Radio Program Evaluation. Progress in Clinical Biological Research, 83, 399-408.

[26] Israel, B.A., Schulz, A.J., Parker, E.A. and Becker, A.B. (1998) Review of Community-Based Research: Assessing Partnership Approaches to Improve Public Health. Annual Review of Public Health, 19, 173-202. http://dx.doi.org/10.1146/annurev.publhealth.19.1.173

[27] News in Brief (2016) Screening Cuts Ovarian Cancer Mortality. Cancer Discovery, 6, OF1. http://cancerdiscovery.aacrjournals.org/content/6/2/OF1 http://dx.doi.org/10.1158/2159-8290.CD-NB2016-003

[28] Abbaszadeh, A., Haghdoost, A.A., Taebi, M. and Kohan, S. (2007) The Relationship between Women's Health Beliefs and Their Participation in Screening Mammography. Asian Pacific Journal of Cancer Prevention, 8, 471-475. 
Submit or recommend next manuscript to SCIRP and we will provide best service for you:

Accepting pre-submission inquiries through Email, Facebook, LinkedIn, Twitter, etc. A wide selection of journals (inclusive of 9 subjects, more than 200 journals)

Providing 24-hour high-quality service

User-friendly online submission system

Fair and swift peer-review system

Efficient typesetting and proofreading procedure

Display of the result of downloads and visits, as well as the number of cited articles

Maximum dissemination of your research work

Submit your manuscript at: http://papersubmission.scirp.org/

Or contact ojepi@scirp.org 